\title{
Knowledge, attitudes, and reported practices among obstetrician- gynecologists in the USA regarding antibiotic prescribing for upper respiratory tract infections
}

\author{
SHADI CHAMANY ${ }^{1}$, JAY SCHULKIN ${ }^{2}$, CHARLES E. ROSE Jr ${ }^{3}$, LAURA E. RILEY $^{4}$, \& \\ RICHARD E. BESSER ${ }^{3}$ \\ ${ }^{1}$ Epidemic Intelligence Service, Division of Applied Public Health Training, Epidemiology Program Office, Centers for Disease \\ Control and Prevention (CDC), Atlanta, GA, USA, ${ }^{2}$ American College of Obstetricians and Gynecologists (ACOG), \\ Department of Research, Washington, DC, USA, ${ }^{3}$ Division of Bacterial and Mycotic Diseases, National Center for Infectious \\ Diseases, CDC, Atlanta, GA, USA, and ${ }^{4}$ Division of Maternal-Fetal Medicine, Vincent Memorial Obstetrics and Gynecology, \\ Massachusetts General Hospital, Boston, MA, USA
}

\begin{abstract}
Background: Knowledge, attitudes, and practices regarding antibiotic prescribing for upper respiratory tract infections (URIs) have not been well described among obstetrician-gynecologists (OB/GYNs). This information is useful for determining whether an $\mathrm{OB} / \mathrm{GYN}$-specific program promoting appropriate antibiotic use would significantly contribute to the efforts to decrease inappropriate antibiotic use among primary care providers.

Methods: An anonymous questionnaire asking about the treatment of URIs was sent to 1031 obstetrician-gynecologists. Results: The overall response rate was $46 \%$. The majority of respondents (92\%) were aware of the relationship between antibiotic use and antibiotic resistance, and respondents estimated that $5 \%$ of their patients had URI symptoms at their office visits. Overall, $56 \%$ of respondents reported that they would prescribe an antibiotic for uncomplicated bronchitis and $43 \%$ for the common cold. OB/GYNs with the fewest years of experience were less likely than those with the most years of experience to report prescribing for uncomplicated bronchitis (Odds ratio (OR) 0.46 , 95\% confidence interval (CI) 0.23 to 0.91 ) or the common cold (OR 0.44 , CI 0.22 to 0.89 ). The majority of respondents ( $60 \%)$ believed that most patients wanted an antibiotic for URI symptoms, with male OB/GYNs being more likely than female OB/GYNs (OR 2.1, CI 1.2 to 3.8) to hold this belief. Both male OB/GYNs (OR 1.9, CI 1.1 to 3.4) and rural practitioners (OR 2.1, CI 1.1 to 4.0) were more likely to believe that it was hard to withhold antibiotics for URI symptoms because other physicians prescribe antibiotics for these symptoms. OB/GYNs who believed that postgraduate training prepared them well for primary care management were more likely than those who did not (OR 2.1, CI 1.1 to 4.2) to believe that they could reduce antibiotic prescribing without reducing patient satisfaction.

Conclusion: Multiple demographic factors affect attitudes and reported practices regarding antibiotic prescribing. However, in view of the low proportion of office visits for URIs, an OB/GYN-specific program is not warranted.
\end{abstract}

Keywords: Antibiotic prescribing, upper respiratory tract infections, obstetrician-gynecologists

\section{Introduction}

The increase in the antibiotic resistance of pneumococci over the past 10 years has been linked to antibiotic use [1-4]. This link was first suggested by the results of both cross-sectional and case-control studies that demonstrated an increased risk of infection with a resistant organism if a person had recently received an antibiotic $[1,5-7]$. The initial public health response to this problem was to implement programs to curb inappropriate antibiotic use [8]. Upper respiratory tract infections (URIs) are of great concern, since they account for the majority of ill office visits and of antibiotic prescribing in the ambulatory setting in the USA [9], despite the fact that many of these infections are viral in nature and do not necessitate antibiotic treatment. Studies among primary care providers have revealed that inappropriate antibiotic prescribing for the treatment of URIs is a result of the following: patient

Correspondence: S. Chamany, 1600 Clifton Rd, Mailstop E-92, Atlanta, GA 30333, USA. Tel: (212) 788 9639. Fax: (212) 7884734.

E-mail: SChamany@cdc.gov

ISSN 1064-7449 print/ISSN 1098-0997 online (C) 2005 Taylor \& Francis Group Ltd

DOI: $10.1080 / 10647440400025579$ 
expectations, physician perception of these expectations, lack of knowledge on the provider's part and external forces, including missed days from work and financial constraints [10-12].

As a result of these findings, the Centers for Disease Control and Prevention (CDC) worked with professional medical societies to develop guidelines for the management of acute respiratory tract illness in adults and children [13, 14] and for appropriate antibiotic use campaigns, combining physician and community-based interventions in the late 1990s [15-18]. The majority of this research and program development focused on pediatricians, internists, family physicians and general practitioners. However, little is known about how obstetriciangynecologists (OB/GYNs) are managing these same illnesses, despite the fact that OB/GYNS form a growing sector within primary care $[19,20]$.

Previous studies examining antibiotic prescribing practices among OB/GYNs have focused on $\mathrm{OB} /$ GYN-specific issues, such as the treatment of gynecologic infections, urinary tract infections and the prevention of perinatal sepsis [20-23]. The results of these studies have been useful in developing infectious disease guidelines for $\mathrm{OB} / \mathrm{GYNs}$, particularly guidelines for the prevention of group B streptococcal disease in infants. After the implementation of the group B streptococcus guidelines of 1996, McGregor et al. [20] showed an increasingly homogeneous approach to group B streptococcus management among surveyed OB/GYNs. This finding suggests that an educational intervention, through the implementation of the group B streptococcus guidelines of 1996, may have played a role in modifying practice behavior, and suggests that this provider population may be receptive to educational interventions such as those that have been successful in the appropriate antibiotic use campaigns [16-18, 24].

We conducted this study to assess OB/GYNs' current knowledge, attitudes, and reported practices regarding the treatment of URIs, an area not previously well described for this specialty. Using this information, we determined whether and how OB/GYNs should be included in the ongoing efforts to curb inappropriate antibiotic use.

\section{Methods}

In June 2002, an anonymous questionnaire was sent to the 409 American College of Obstetricians and Gynecologists (ACOG) Fellows of the Collaborative Ambulatory Research Network (CARN) and to 622 randomly selected non-CARN ACOG Fellows. Established in 1990, the CARN consists of a group of ACOG Fellows who voluntarily participate in surveys to help ACOG monitor prevailing clinical obstetric and gynecologic practices. Members receive approximately four ACOG-sponsored surveys annually, on a range of topics. Participants have been chosen to reflect the age and sex distribution of all ACOG Fellows. A second mailing was sent to nonresponders from both groups approximately 6 weeks later. The appropriate sample size was calculated from previous survey response rates of approximately $60 \%$, and expected proportions approaching 50\% with 95\% confidence intervals (CIs). The study protocol was reviewed by an institutional review board of the CDC and found to be exempt from the need for human subjects review.

Because we wanted to characterize current ambulatory practices of providers within the USA who manage URIs in non-pregnant patients, we excluded from the final analysis respondents who did not see patients in 2001, who were currently in a training program, whose practice was outside the USA, or who refer patients with URIs to another provider for care. We also excluded individuals who only see obstetric patients because of the potential bias that pregnancy might exert on antibiotic prescribing, and individuals who did not provide an estimate of the number of non-pregnant patients within their practice.

Question format for provider demographic characteristics was primarily multiple-choice. Questions assessing provider knowledge and attitudes regarding the treatment of URIs in non-pregnant women were in the form of a 5-point Likert scale. Two clinical scenarios were proposed, also in the form of a Likert scale, to assess reported antibiotic prescribing practices for non-pregnant women, i.e., uncomplicated bronchitis defined as a cough illness with purulent sputum for 5 days and no fever, and the common cold defined as a URI with purulent nasal discharge for 5 days without fever or cough. Comments could be added at the end of the questionnaire. The number of years of $\mathrm{OB} / \mathrm{GYN}$ experience was divided into quartiles, i.e. lowest 0 to 7 years, low 8 to 14 years, medium 15 to 21 years and high $\geqslant 22$ years. Location of practice was categorized as rural or non-rural. The number of months of non-OB/GYN postgraduate outpatient training (i.e., internal medicine outpatient clinic, pediatric outpatient clinic) was divided into $<6$ months and $\geqslant 6$ months. Likert scale responses were dichotomized, excluding the "no opinion" responses.

Survey responses were double-entered to minimize data entry errors. Statistical analysis was performed using SAS 8.2 (SAS Institute, Cary, NC, USA). Descriptive analysis of the sample of individuals who completed all of the demographic and postgraduate training questions was performed using the chi-squared test for categorical variables and the median two-sample test for continuous 
variables. For each knowledge item, attitude (about patient expectations), and reported practice outcome variable, provider characteristics were independently assessed using Mantel-Haenszel-Cochran summary odds ratios (ORs) and 95\% CIs. The characteristics examined included gender, CARN status, number of years of OB/GYN experience, location of practice, number of months of non-OB/GYN postgraduate outpatient training, believing postgraduate training prepared them well for primary care management, and believing continuing medical education (CME) is useful for updates of the clinical management of URIs. All variables significant at $p<0.15$ on univariate analysis were evaluated in multivariable models using logistic regression. The number of cases for each model varied because the number of "no opinion" responses varied among the different outcomes variables. Because the CARN group differed from the non-CARN group in response rate and by the number of years of experience, all multivariable models controlled for CARN status and the number of years of OB/GYN experience. In addition, we controlled for gender since this variable was a potential confounder.

\section{Results}

Completed surveys were received from 265 (65\%) of the 409 CARN members and $254(41 \%)$ of the 622 non-CARN ACOG Fellows. Of these 519 respondents, $91(18 \%)$ were excluded from the final analysis, i.e., 39 CARN respondents (15\%), and 52 non-CARN respondents (20\%), leaving 226 (61\%) of 370 eligible CARN respondents and $202(35 \%)$ of 570 eligible non-CARN respondents. The 91 respondents who were excluded comprised 12 who did not see patients in 2001, 9 who were currently in training, 20 who had a practice outside the USA or in an unknown location 8, (4 pairs) who had duplicate study numbers, 1 who refused, 15 who referred patients with URIs to another provider for care, 14 who saw obstetric patients only and 12 who did not provide information about the number of nonpregnant patients in their practice. An additional group of 44 individuals (15 CARN, 29 non-CARN) did not complete all of the demographic and postgraduate training questions. This group differed from the final sample only in containing a higher proportion of respondents who saw non-pregnant patients only $(27 \%$ versus $15 \%, p=0.03)$. No information was available on the non-respondents because of the anonymous nature of the survey.

The final sample consisted of 384 respondents, whose characteristics are shown in Table I. The CARN respondents were older and had a greater number of years of OB/GYN experience than did the non-CARN respondents. The CARN group had a higher proportion of respondents with 6 months or more of non-OB/GYN postgraduate outpatient training than did the non-CARN group. As a group, respondents identified CME lecture series (65\%), OB/GYN meetings (63\%), newsletters (55\%) and peer-reviewed journal articles (54\%) as useful methods to disseminate guidelines and practice updates.

On average, respondents estimated that 5\% (interquartile range [IQR] $2 \%$ to $10 \%$ ) of their non-pregnant patients presented with symptoms of a URI when they came for an office visit, and of these $30 \%$ (IQR $10 \%$ to $65 \%$ ) would request an antibiotic for their symptoms. When asked if they would prescribe an antibiotic for two common URIs (Table II), $56 \%$ and $43 \%$ of respondents reported that they would prescribe antibiotics for uncomplicated bronchitis and the common cold, respectively.

To determine what is driving antibiotic prescribing in $\mathrm{OB} / \mathrm{GYN}$ offices, we assessed provider knowledge and attitudes about the treatment of URIs (Table III), and $92 \%$ of respondents agreed that there would be a reduced risk of antibiotic resistance infections if fewer antibiotics were prescribed. The majority of respondents believed that most of their patients thought that they should prescribe an antibiotic for URI symptoms (60\%) and felt confident that the antibiotic that they would prescribe would be necessary (64\%). Almost half $(47 \%)$ of respondents believed that they could not decrease antibiotic prescribing without decreasing patient satisfaction. The respondents who felt that it was hard to withhold antibiotics for URI symptoms when other physicians prescribed antibiotics for these symptoms were more likely than their counterparts to believe that most of their patients thought that they should prescribe an antibiotic for a URI (OR 17.7, CI 6.3 to $51.5, p<0.0001$ ) and that they could not reduce antibiotic prescribing without reducing patient satisfaction (OR 4.2, CI 2.2 to $8.1, p<0.0001)$.

Provider characteristics that were associated with reported practices and attitudes on univariate analysis were the following. Men were more likely than women to report that they would prescribe an antibiotic for uncomplicated bronchitis $(66 \%$ versus $54 \%, p=0.03)$ or the common cold $(53 \%$ versus $40 \%, p=0.02$ ), to believe most of their patients thought that they should prescribe an antibiotic for URI symptoms $(72 \%$ versus $63 \%, p=.12)$ and to believe that it was hard to withhold antibiotics for URI symptoms because other physicians prescribed antibiotics for these symptoms (38\% versus $21 \%$, $p=0.001$ ).

Individuals with fewer number of years of experience were less likely to report antibiotic prescribing for uncomplicated bronchitis (chi square for trend, 
Table I. Characteristics of respondents.

\begin{tabular}{|c|c|c|c|}
\hline Provider characteristic & Total $(n=384)$ & CARN $(n=211)$ & Non-CARN $(n=173)$ \\
\hline${ }^{\star}$ Median age (range) in years & 47 (29 to 80$)$ & 48 (32 to 66$)$ & 45 (29 to 80$)$ \\
\hline Male gender $(\%)$ & 57 & 59 & 54 \\
\hline${ }^{\star}$ Median years of $\mathrm{OB} / \mathrm{GYN}$ experience (range) & $15(0$ to 50$)$ & 16 (3 to 40$)$ & $11(0$ to 50$)$ \\
\hline \multicolumn{4}{|l|}{${ }^{\star}$ Category of years of $\mathrm{OB} / \mathrm{GYN}$ experience $(\%)$} \\
\hline lowest quartile (0-7 years) & 23 & 14 & 33 \\
\hline low quartile (8-14 years) & 25 & 26 & 24 \\
\hline medium quartile (15-21 years) & 26 & 31 & 21 \\
\hline highest quartile ( $\geqslant 22$ years) & 26 & 29 & 22 \\
\hline \multicolumn{4}{|l|}{ Practice type $(\%)$} \\
\hline solo or two clinicians & 29 & 32 & 25 \\
\hline multispecialty group & 12 & 15 & 10 \\
\hline $\mathrm{OB} / \mathrm{GYN}$ group & 42 & 39 & 44 \\
\hline university practice & 9 & 8 & 12 \\
\hline HMO staff model & 2 & 1 & 2 \\
\hline military & 2 & 1 & 2 \\
\hline community health center & 1 & 1 & 2 \\
\hline other & 3 & 3 & 3 \\
\hline \multicolumn{4}{|l|}{ Practice location (\%) } \\
\hline urban & 30 & 30 & 30 \\
\hline suburban & 54 & 54 & 54 \\
\hline rural & 15 & 16 & 14 \\
\hline other & 1 & 0 & 2 \\
\hline \multicolumn{4}{|l|}{ Region of country (\%) } \\
\hline Midwest & 19 & 20 & 19 \\
\hline Northeast & 20 & 18 & 23 \\
\hline West & 26 & 27 & 23 \\
\hline South & 35 & 35 & 35 \\
\hline \multicolumn{4}{|l|}{ Type of patient seen in practice (\%) } \\
\hline pregnant and non-pregnant & 85 & 86 & 85 \\
\hline non-pregnant only & 15 & 14 & 15 \\
\hline \multicolumn{4}{|l|}{${ }^{\star}$ Months of non-OB/GYN outpatient training } \\
\hline$<6$ months $(\%)$ & 77 & 72 & 83 \\
\hline$\geqslant 6$ months $(\%)$ & 23 & 28 & 17 \\
\hline \multicolumn{4}{|c|}{$\begin{array}{l}\text { Believed postgraduate training prepared them well for } \\
\text { primary care management }(\%)\end{array}$} \\
\hline yes & 40 & 36 & 45 \\
\hline no & 60 & 64 & 55 \\
\hline \multicolumn{4}{|c|}{$\begin{array}{l}\text { Believed CME for updates on URI management was } \\
\text { helpful (\%) }\end{array}$} \\
\hline yes & 38 & 38 & 38 \\
\hline no & 29 & 32 & 25 \\
\hline no opinion & 33 & 30 & 37 \\
\hline
\end{tabular}

CARN, Collaborative Ambulatory Research Network; ${ }^{\star} p<0.05$, CARN versus non-CARN.

Table II. Reported practices among OB/GYNs regarding treatment of URI in non-pregnant patients ${ }^{\star}(n=346)$.

\begin{tabular}{lccc}
\hline Clinical scenario & $\begin{array}{c}\text { Would prescribe } \\
\text { antibiotic (\%) }\end{array}$ & $\begin{array}{c}\text { Would not prescribe } \\
\text { antibiotic (\%) }\end{array}$ & Unsure (\%) \\
\hline $\begin{array}{l}\text { Acute bronchitis/cough illness for } 5 \text { days with purulent sputum; } \\
\text { no fever; normal lung exam }\end{array}$ & $195(56)$ & $124(36)$ & $27(8)$ \\
$\begin{array}{l}\text { Upper respiratory tract infection, purulent nasal discharge for } 5 \\
\text { days } \\
\quad \text { without improvement; no fever; no cough; otherwise normal } \\
\quad \text { exam }\end{array}$ & $147(43)$ & $163(47)$ & $36(10)$ \\
\hline
\end{tabular}

$p=0.008$ ) or the common cold (chi square for trend, $p=0.002$ ), less likely to believe that it was hard to withhold antibiotics (chi square for trend, $p=0.002$ ) but more likely to believe that most of their patients wanted an antibiotic for a URI (chi square for trend, $p=0.03$ ). Rural practitioners were more likely than 
Table III. *Distribution of responses to knowledge and attitude questions regarding treatment of URI in non-pregnant patients among OB/ GYNs.

\begin{tabular}{|c|c|c|c|}
\hline Statement & Agree (\%) & Disagree $(\%)$ & No opinion (\%) \\
\hline $\begin{array}{l}\text { My non-pregnant patients will have a reduced risk of antibiotic resistant infections if I } \\
\text { prescribe fewer antibiotics }(n=346)\end{array}$ & $318(92)$ & $7(2)$ & $21(6)$ \\
\hline $\begin{array}{l}\text { Most of my non-pregnant patients think I should prescribe antibiotics for cough, cold } \\
\text { and flu symptoms }(n=347)\end{array}$ & $208(60)$ & $97(28)$ & $42(12)$ \\
\hline $\begin{array}{l}\text { When I prescribe an antibiotic for a respiratory tract infection in a non-pregnant } \\
\text { patient, I am confident that the antibiotic is necessary }(n=347)\end{array}$ & $223(64)$ & $82(24)$ & $42(12)$ \\
\hline $\begin{array}{l}\text { I could reduce my antibiotic prescribing without any decrease in patient satisfaction } \\
(n=346)\end{array}$ & $104(30)$ & $163(47)$ & 79 (23) \\
\hline $\begin{array}{l}\text { It is hard for me to withhold antibiotics for cough, cold and flu symptoms because } \\
\text { other clinicians in my community prescribe antibiotics for these illnesses }(n=347)\end{array}$ & $91(26)$ & $207(60)$ & $49(14)$ \\
\hline
\end{tabular}

$\star^{*} n$ varies because of missing data.

non-rural practitioners to report that it was hard to withhold antibiotics for URI symptoms ( $46 \%$ versus $27 \%, p=0.009)$ and less likely to believe that they could reduce antibiotic prescribing in their practice without reducing patient satisfaction $(19 \%$ versus $43 \%, p=0.004)$. In our study population, male $\mathrm{OB} /$ GYNs had more years of experience than female OB/ GYNs (18 years versus 11 years, $p<0.0001$ ) and made up a larger proportion of those practicing in rural areas compared with female OB/GYNs $(69 \%$ versus $31 \%, p=0.04)$.

Individuals who believed that postgraduate training prepared them well for primary care management were more likely to feel confident that an antibiotic they prescribed was necessary $(79 \%$ versus $69 \%$, $p=0.07)$. Individuals who believed that postgraduate training prepared them well for primary care management ( $48 \%$ versus $33 \%, p=0.02$ ) or believed that CME was useful for updates of the clinical management of URIs ( $45 \%$ versus $29 \%, p=0.04$ ) were more likely than those who did not hold these opinions to believe that they could reduce antibiotic prescribing in their practice without reducing patient satisfaction.

Multivariable analysis was performed to determine which provider characteristics were independently associated with particular attitudes or reported practices. Controlling for CARN status, gender and the numbers of years of OB/GYN experience, male OB/ GYNs were more likely than female OB/GYNs (OR 2.1 , CI 1.2 to $3.8, p=0.01$ ) to believe that most of their patients thought they should prescribe an antibiotic for URI symptoms. Both male OB/GYNs (OR 1.9, CI 1.1 to $3.4, p=0.02)$ and rural practitioners (OR 2.2, CI 1.1 to $4.0, p=0.03$ ) were more likely to believe that it was hard to withhold antibiotics for URI symptoms because other physicians prescribe antibiotic for these symptoms. Respondents who thought that postgraduate training prepared them well for primary care management were more likely than those who did not (OR 2.1, CI 1.1 to $4.2, p=0.03$ ) to believe that they could reduce antibiotic prescribing without reducing patient satisfaction. Providers with years of experience in the lowest quartile (0 to 7 years) were less likely than those with years of experience in the highest quartile $(\geqslant 22$ years) to report antibiotic prescribing for uncomplicated bronchitis (OR 0.46, CI 0.23 to $0.91, p=0.03$ ) and the common cold (OR 0.44, CI 0.22 to $0.89, p=0.08$ ), but were more likely to believe that most of their patients thought that they should prescribe an antibiotic for a URI (OR 5.0, CI 2.1 to $11.8, p=0.005$ ).

Because the expectations of patients, as perceived by physicians, are presumably not the only attitudes influencing clinical decision-making, we asked how various clinical characteristics of a non-pregnant woman with URI symptoms, etiology unknown, would increase or decrease the likelihood of prescribing an antibiotic (Table IV). The presence of a productive cough with purulent sputum, a second visit for the same symptoms, and a fever with purulent nasal discharge all increased the likelihood of prescribing an antibiotic. Neither a statement from the woman that she had received an antibiotic for a similar problem in the past, nor concerns about her need to return to work, had much effect on the prescriber's likelihood of prescribing an antibiotic. When asked if antibiotic prescribing would be altered if the patient was pregnant, $201(66 \%)$ of 304 respondents who saw both obstetric and gynecologic patients reported that it would make no difference and $76(25 \%)$ reported that they would be more likely to prescribe an antibiotic.

The comments that respondents added at the end of the questionnaire emphasized the findings described above. Some respondents stated that they succumbed to patient pressure and time constraints by prescribing antibiotics rather than explain to patients why they did not need antibiotics. Others expressed concern about physicians in their own practices or within the community who "throw antibiotics at everything" or "take the easy way 
Table IV. *The influence of various patient characteristics on the likelihood of provider antibiotic prescribing for a non-pregnant woman with a URI, etiology unknown.

\begin{tabular}{lccc}
\hline Characteristic & $\begin{array}{c}\text { Would increase } \\
\text { prescribing }(\%)\end{array}$ & $\begin{array}{c}\text { Would decrease } \\
\text { prescribing (\%) }\end{array}$ & No change (\%) \\
\hline Productive cough with purulent sputum $(n=346)$ & $315(91)$ & $3(1)$ & $28(8)$ \\
Second visit for the same problem $(n=344)$ & $280(81)$ & $5(2)$ & $59(17)$ \\
Fever $\left(\geqslant 100.4^{\circ} \mathrm{F}\right.$ or $\left.38^{\circ} \mathrm{C}\right)(n=347)$ & $253(73)$ & $5(1)$ & $89(26)$ \\
Purulent nasal discharge $(n=347)$ & $224(65)$ & $8(2)$ & $115(33)$ \\
Patient states she received an antibiotic for similar symptoms in the & $92(27)$ & $36(10)$ & $218(63)$ \\
$\quad$ past $(n=346)$ & $40(12)$ & $26(7)$ & $281(81)$ \\
Patient needs to return to work $(n=347)$ & & & \\
\hline
\end{tabular}

${ }^{\star} n$ varies because of missing data.

out" rather than take the time to discuss issues with patients.

\section{Discussion}

Knowledge, attitudes and reported practices among $\mathrm{OB} / \mathrm{GYNs}$ regarding the treatment of URIs were similar to those of previously surveyed primary care providers [9, 10, 25-29]. In our study, providers were aware of the risk of resistant infections with increasing antibiotic use, but reported inappropriate prescribing practices and expressed attitudes that might promote these practices.

A high proportion of respondents reported that they would prescribe antibiotics for two common conditions, uncomplicated bronchitis and the common cold, for which antibiotics are not usually indicated. Previous studies have shown similar rates of prescribing among a variety of specialties, ranging from $66 \%$ to $80 \%$ for uncomplicated bronchitis and $25 \%$ to $60 \%$ for the common cold $[10,28-30]$. In a study by Gonzales et al. [28], the investigators found that rural practitioners were more likely than were non-rural practitioners to prescribe antibiotics for URIs in adults. One finding unique to our study was the association of male gender of the practitioner, independent of the number of years of experience, with attitudes that might promote inappropriate prescribing for URIs. It is likely that there are other factors associated with male gender that influence antibiotic prescribing that we were unable to assess in our survey. In addition, the finding that providers with the fewest years of experience reported less antibiotic prescribing for these conditions than did those with the most experience may be a function of proximity to postgraduate training, a time when appropriate antibiotic use messages may be more frequently conveyed.

Historically, provider attitudes and prescribing have been linked to patient demand for antibiotics as well as to physician perception of these demands $[10,29]$. Although we did not look at actual prescribing as it is related to particular attitudes in our study, our findings suggest that the respondents who reported that it was hard to withhold antibiotics felt this way because they believed that their patients expected antibiotics for URI symptoms and that, if these patients did not receive an antibiotic, they would not be satisfied and would then seek care elsewhere. In addition, physicians might consider an antibiotic necessary because of patient expectation, rather than basing the decision on clinical indications.

Although the majority of respondents appreciated the relationship between antibiotic use and resistance, they felt that the presence of purulent discharge from the respiratory tract, which is not an accurate indicator of a bacterial infection that requires antibiotic therapy $[31,32]$, warranted an antibiotic. However, in the absence of other symptoms suggesting an acute bacterial infection, such as fever or purulent discharge for $\geqslant 7$ days, antibiotics are not indicated. In a study by Watson et al. [10], surveyed pediatricians and family physicians felt that antibiotics would decrease the numbers of days of illness in a child with purulent nasal discharge, and this belief may have been prevalent among our respondents as well.

Some important limitations to our study are worth mentioning. The survey response rate was low, especially in comparison with the $60 \%$ to $70 \%$ response rates that are typical for surveys administered among this group. This low response rate may be attributable to the subject matter, since the usual surveys focus on $\mathrm{OB} / \mathrm{GYN}$-specific issues rather than on primary care matters. Because this questionnaire was anonymous, we were unable to compare the characteristics of a sample of non-respondents with those of the respondents. This survey was a selfadministered questionnaire relying on recall and reported practices. Since this study was not designed to link attitudes to actual prescribing, there may have been information bias towards providing answers that the respondent thought the investigators wanted 
to hear. This possibility could have led to underestimates of the prevalence of inappropriate attitudes and prescribing behaviors.

Educational interventions for appropriate antibiotic use for URIs in the USA are ongoing. Studies evaluating these programs have demonstrated a decrease in inappropriate antibiotic prescribing as a result $[16-18,24]$. Although OB/GYN knowledge, attitudes and reported practices were similar to those of other providers, our study, as well as previous studies, suggested that URIs account for a small proportion of office visits to this specialty group [33, 34]. Therefore, additional interventions focusing on $\mathrm{OB} / \mathrm{GYN}$ s alone may not be justified, since such interventions would have a small impact on the overall inappropriate use of antibiotics in the USA. However, including $\mathrm{OB} / \mathrm{GYNs}$ in the ongoing interventions directed at other primary care providers would be a useful way to provide education regarding the treatment of URIs among OB/GYNs providing primary care.

\section{Acknowledgement}

This work was supported in part by a grant from HRSA-MCHB.

\section{References}

1. Arnold KE, Leggiadro RJ, Breiman RF, et al. Risk factors for carriage of drug-resistant Streptococcus pneumoniae among children in Memphis, Tennessee. J Pediatr 1996;128: 757-764

2. Duchin JS, Breiman RF, Diamond A, et al. High prevalence of multidrug-resistant Streptococcus pneumoniae among children in a rural Kentucky community. Pediatr Infect Dis J 1995;14:745-750.

3. Hofmann J, Cetron MS, Farley MM, et al. The prevalence of drug-resistant Streptococcus pneumoniae in Atlanta. N Engl J Med 1995;333:481-486.

4. Jacobs MR. Increasing importance of antibiotic-resistant Streptococcus pneumoniae in acute otitis media. Pediatr Infect Dis J 1996;15:940-943.

5. Arason VA, Kristinsson KG, Sigurdsson JA, Stefansdottir G, Molstad S, Gudmundsson S. Do antimicrobials increase the carriage rate of penicillin resistant pneumococci in children? Cross sectional prevalence study. BMJ 1996;313:387-391.

6. Tan TQ, Mason Jr EO, Kaplan SL. Penicillin-resistant systemic pneumococcal infections in children: a retrospective case-control study. Pediatrics 1993;92:761-767.

7. Schrag SJ, Pena C, Fernandez J, et al. Effect of short-course, high-dose amoxicillin therapy on resistant pneumococcal carriage: a randomized trial. JAMA 2001;286:49-56.

8. Emmer CL, Besser RE. Combating antibiotic resistance: intervention programs to promote appropriate antibiotic use. Infections in Medicine 2002;19:160-173.

9. McCaig LF, Hughes JM. Trends in antimicrobial drug prescribing among office-based physicians in the USA. JAMA $1995 ; 273: 214-219$.
10. Watson RL, Dowell SF, Jayaraman M, Keyserling H, Kolczak M, Schwartz B. Antimicrobial use for pediatric upper respiratory infections: reported practice, actual practice, and parent beliefs. Pediatrics 1999;104:1251-1257.

11. Wilson AA, Crane LA, Barrett PH, Gonzales R. Public beliefs and use of antibiotics for acute respiratory illness. J Gen Intern Med 1999;14:658-662.

12. Barden LS, Dowell SF, Schwartz B, Lackey C. Current attitudes regarding use of antimicrobial agents: results from physicians' and parents' focus group discussions. Clin Pediatr (Phila) 1998;37:665-671.

13. Dowell SF, Maray SM, Phillips WR, Gerber MA, Schwartz B. Principles of judicious use of antimicrobial agents for pediatric upper respiratory tract infections. Pediatrics 1998;101:163184.

14. Gonzales R, Bartlett JG, Besser RE, Cooper RJ, Hickner JM, Hoffman JR, Sande MA. Guidelines for appropriate antibiotic use for treatment of acute respiratory tract infections in adults. Ann Intern Med 2001;134:479-529.

15. Besser RE. How to alter prescription patterns: promoting appropriate antibiotic use. In: Soulsby L, Wilbur R, editors. Antimicrobial resistance. Proceedings of a meeting held in Washington, 4-5th May, 2000. ICSS 247. London: RSM Press; 2001. pp 157-158.

16. Finkelstein JA, Davis RL, Dowell SF, et al. Reducing antibiotic use in children: a randomized trial in 12 practices. Pediatrics 2001;108:1-7.

17. Gonzales R, Steiner JF, Lum A, Barrett Jr PH. Decreasing antibiotic use in ambulatory practice: impact of a multidimensional intervention on the treatment of uncomplicated acute bronchitis in adults. JAMA 1999;281:1512-1519.

18. Hennessy TW, Petersen KM, Bruden D, et al. Changes in antibiotic-prescribing practices and carriage of penicillinresistant Streptococcus pneumoniae: a controlled intervention trial in rural Alaska. Clin Infect Dis 2002;34:1543-1550.

19. Gallagher TC, Geling O, Comite F. Use of multiple providers for regular care and women's receipt of hormone replacement therapy counseling. Med Care 2001;39:1086-1096.

20. McGregor JA, Hager WD, Gibbs RS, Schmidt L, Schulkin J. Assessment of office-based care of sexually transmitted diseases and vaginitis and antibiotic decision-making by obstetrician-gynecologists. Infect Dis Obstet Gynecol 1998; 6:247-251.

21. Mercer BM, Carr TL, Beazley DD, Crouse DT, Sibai BM. Antibiotic use in pregnancy and drug-resistant infant sepsis. Am J Obstet Gynecol 1999;181:816-821.

22. Gibbs RS, McGregor JA, Mead PB, Eschenbach DA, Hager WD, Sweet RL. A survey of practices in infectious diseases by obstetrician-gynecologists. Obstet Gynecol 1994;83: 631-636.

23. Watt JP, Schuchat A, Erickson K, Honig JE, Gibbs R, Schulkin J. Group B streptococcal disease prevention practices of obstetrician-gynecologists. Obstet Gynecol 2001;98:7-13.

24. Belongia EA, Sullivan BJ, Chyou PH, Madagame E, Reed $\mathrm{KD}$, Schwartz B. A community intervention trial to promote judicious antibiotic use and reduce penicillin-resistant Streptococcus pneumoniae carriage in children. Pediatrics 2001;108:575-583.

25. Metlay JP, Stafford RS, Singer DE. National trends in the use of antibiotics by primary care physicians for adult patients with cough. Arch Intern Med 1998;158:1813-1818.

26. Linder JA, Stafford RS. Antibiotic treatment of adults with sore throat by community primary care physicians: a national survey, 1989-1999. JAMA 2001;286:1181-1186. 
27. Steinman MA, Landefeld CS, Gonzales R. Predictors of broad-spectrum antibiotic prescribing for acute respiratory tract infections in adult primary care. JAMA 2003;289: 719-725.

28. Gonzales R, Steiner JF, Sande MA. Antibiotic prescribing for adults with colds, upper respiratory tract infections, and bronchitis by ambulatory care physicians. JAMA 1997;278: 901-904.

29. Hamm RM, Hicks RJ, Bemben DA. Antibiotics and respiratory infections: do antibiotic prescriptions improve outcomes? J Okla State Med Assoc 1996;89:267-274.

30. Mainous III AG, Hueston WJ, Clark JR. Antibiotics and upper respiratory infection: do some folks think there is a cure for the common cold? J Fam Pract 1996;42:357-361.
31. Todd JK, Todd N, Damato J, Todd WA. Bacteriology and treatment of purulent nasopharyngitis: a double blind, placebo-controlled evaluation. Pediatr Infect Dis J 1984;3: 226-232.

32. Steinweg KK. Natural history and prognostic significance of purulent rhinitis. J Fam Pract 1983;17:61-64.

33. Gibbs RS, Eschenbach DA. Use of antibiotics to prevent preterm birth. Am J Obstet Gynecol 1997;177:375-380.

34. Schappert S. Office visits to obstetricians and gynecologists: USA, 1989-90. Advance data from vital and health statistics 1992;223. 


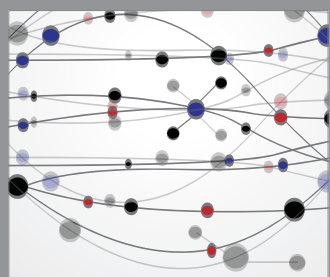

The Scientific World Journal
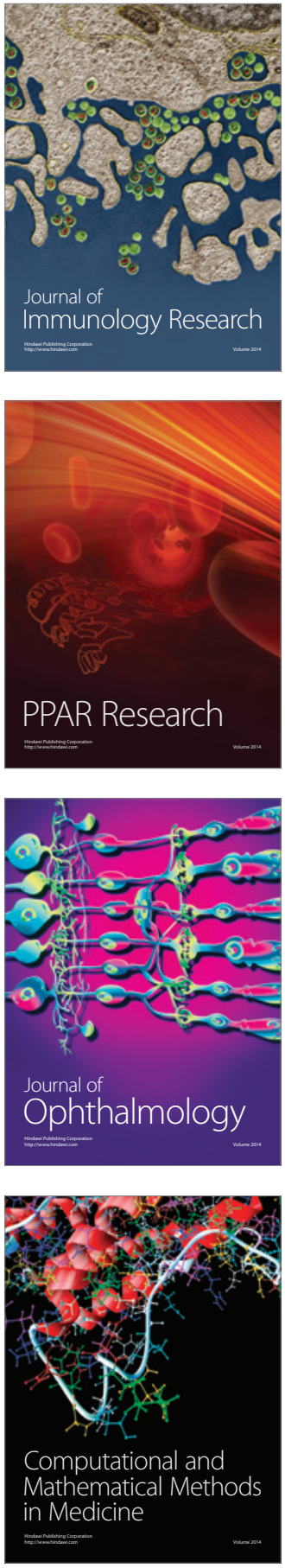

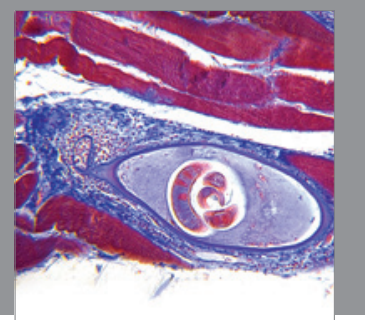

Gastroenterology

Research and Practice
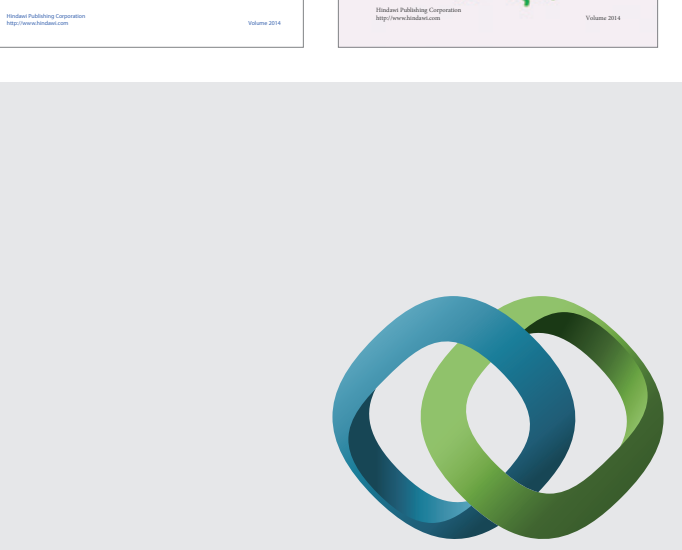

\section{Hindawi}

Submit your manuscripts at

http://www.hindawi.com
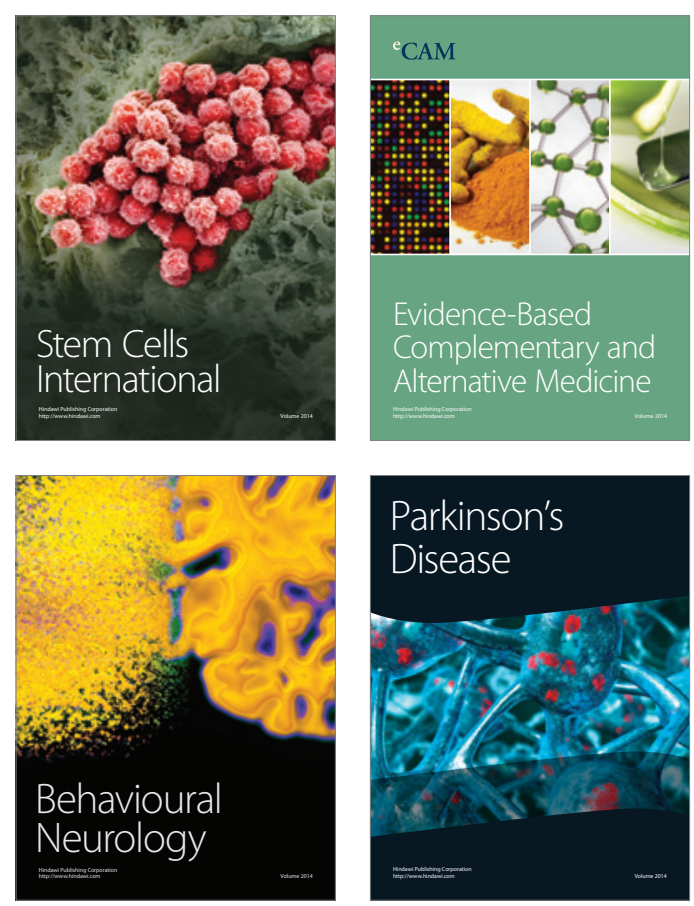

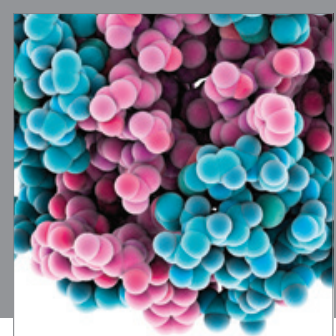

Journal of
Diabetes Research

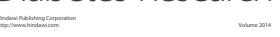

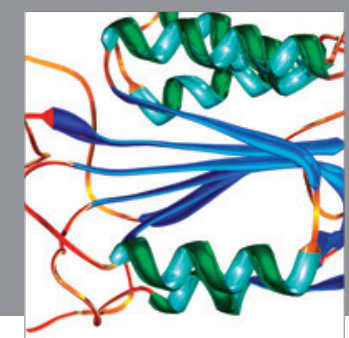

Disease Markers
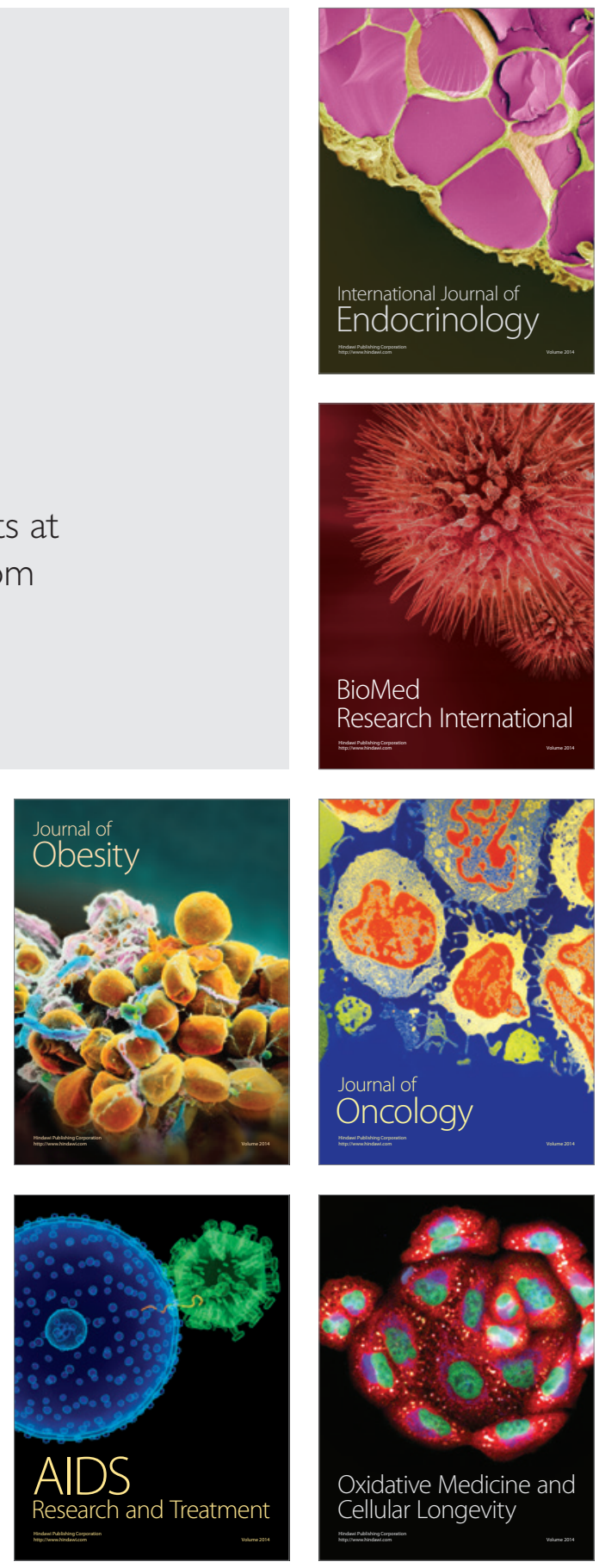